\title{
Lei de Benford aplicada à auditoria da reforma do Aeroporto Internacional de Minas Gerais
}

\author{
Maurício Soares Bugarin \\ Universidade de Brasília (UnB) \\ Flávia Ceccato Rodrigues da Cunha \\ Tribunal de Contas da União (TCU)
}

A Lei de Benford propõe que as frequências dos primeiros dígitos dos valores em um banco de dados sejam decrescentes do 1 ao 9; o primeiro dígito 1 apareceria em, aproximadamente, $30 \%$ dos dados, enquanto o 9 não atingiria $5 \%$ desses valores. Este trabalho apresenta uma seleção de testes usados na literatura empírica e tem como objetivo principal verificar se um algoritmo geral adotado para a seleção da amostra de auditoria é aplicável à planilha da obra de reforma do Aeroporto Internacional de Minas Gerais. Os resultados são comparados com aqueles encontrados na auditoria do Tribunal de Contas da União, que adota a metodologia da Curva $A B C$ para a seleção da amostra, mostrando que pelo menos $86 \%$ do valor total do sobrepreço identificado seria exposto caso a nova metodologia tivesse sido aplicada.

Palavras-chave: auditoria, análise de dados, metodologia, algoritmo, Lei de Benford

[Artigo submetido em 30 de agosto de 2016. Aprovado em 19 de abril de 2017.] 


\section{Aplicación de la Ley de Benford en la auditoria de la reforma del Aeropuerto Internacional} de Minas Gerais

La Ley de Benford propone que las frecuencias de los primeros dígitos de los valores en una base de datos disminuyen del 1 al 9; el dígito 1 aparecería en aproximadamente el 30\% de los datos, mientras que el 9 no llegaría a 5\% de estos valores. Este trabajo presenta una selección de los estudios utilizados en la literatura empírica y su principal objetivo e verificar si un algoritmo general que se utiliza para seleccionar la muestra de auditoría se aplica a la planilla de la reforma del Aeropuerto Internacional de Minas Gerais. Los resultados se comparar con aquellos encontrados en la auditoría del Tribunal de Cuentas de la Unión, que adopta la metodología de la curva de $A B C$ para la selección de la muestra, lo que demuestra que al menos el $86 \%$ del sobreprecio total de identificadas estaría expuesto si se hubiera aplicado la nueva metodología.

Palabras-clave: auditoría, análisis de datos, metodología, algoritmo, Ley de Benford

\section{Application of Benford's Law to the audit of Minas Gerais International Airport's remodeling works}

Benford Law establishes that the frequencies of the first digits of numbers in a database decrease from 1 to 9; the first digit 1 would appear in approximately $30 \%$ of the data, while first digit 9 would appear in less than $5 \%$ of these values. This paper presents a selection of tests used in the empirical literature and its main objective is to check if a general algorithm adopted for the selection of the audit sample is applicable to the budget spreadsheet of the Minas Gerais International Airport renovation. The results are compared with those found in the audit of the Federal Court of Accounts, which adopts the ABC Curve methodology for sample selection, showing that at least $86 \%$ of the total value of the identified overprice would be exposed had the new methodology been applied.

Keywords: audit, data analysis, methodology, algorithm, Benford's Law 


\section{Introdução}

Para se auditar uma obra pública, é preciso avaliar a qualidade da construção em si e verificar se os preços dos itens do orçamento estão de acordo com os valores de mercado. Como, em muitos casos, as planilhas orçamentárias possuem numerosos itens e não existe tempo hábil para realizar o exame de todos, os órgãos de controle, em geral, adotam a Curva $A B C$ para selecionar a amostra de auditoria. Essa metodologia consiste na seleção de cerca de $20 \%$ dos serviços (os mais caros da obra), em ordem decrescente de relevância financeira, totalizando aproximadamente $80 \%$ do valor total do orçamento.

Assim, a curva ABC considera apenas a relevância financeira dos serviços, sem levar em conta possíveis indícios de manipulação dos dados. O ideal seria encontrar uma ferramenta para a seleção da amostra que considerasse, além dos preços dos itens, indícios de manipulação desses valores. A Lei de Benford oferece essa possibilidade.

O objetivo deste trabalho é testar a aplicabilidade de uma nova metodologia para seleção de amostra de auditoria de obra pública baseada na Lei de Benford desenvolvida em estudos recentes (CUNHA, 2013; BugArIn; CUNHA, 2015; CUNHA; Bugarin; PORTugal, 2016). Essa metodologia é aqui aplicada à auditoria do orçamento da obra de reforma do Aeroporto Internacional Tancredo Neves (MG), um dos principais aeroportos em operação no Brasil ${ }^{1}$. A obra foi selecionada por ser uma construção de grande porte, bastante relevante para a infraestrutura que viria a dar suporte aos jogos da Copa do Mundo de 2014 e das Olimpíadas de 2016, por apresentar um significativo volume de dados $(N=2081)$ e pela possibilidade de comparação dos resultados dos testes com a análise de preços empreendida pelo Tribunal de Contas da União (TCU).

O principal resultado encontrado é que a nova metodologia se configura como uma poderosa ferramenta para a seleção da amostra de auditoria, uma vez que pelo menos $86 \%$ do valor total do sobrepreço identificado pelo TCU teria sido exposto caso a amostra proposta por essa metodologia tivesse sido auditada. Ademais, a amostra corresponde a menos de $71 \%$ do valor total da obra, abaixo dos $80 \%$ auditados pelo TCU. Vale notar que possivelmente outros sobrepreços teriam ainda sido identificados, caso todos os itens na amostra proposta pela nova metodologia tivessem sido auditados.

\footnotetext{
${ }^{1}$ Segundo dados apresentados no Movimento Operacional da Rede Infraero, de janeiro a dezembro de 2013, um total de 10,3 milhões de passageiros foram transportados no Aeroporto Internacional Tancredo Neves. Entre os aeroportos brasileiros, é o $5^{\circ}$ (depois de Guarulhos, Congonhas, Galeão e Brasília). Disponível em: http://www. bh-airport.com.br/ (acesso em 31/07/2015).
} 
Além desta introdução, o artigo está organizado da forma descrita a seguir. A segunda seção descreve brevemente os antecedentes da Lei de Benford. A terceira seção apresenta os testes da Lei de Benford baseados nas frequências dos dígitos. A quarta seção mostra um resumo da auditoria do TCU na obra de reforma do Aeroporto Internacional Tancredo Neves (MG). A quinta seção trata da metodologia baseada no algoritmo proposto por Bugarin e Cunha (2015) e detalhado de forma pormenorizada em Cunha, Bugarin e Portugal (2016) aplicada à obra em tela. A sexta seção confronta os resultados obtidos mediante o uso do algoritmo com a análise do TCU. Finalmente, a última seção expõe as conclusões.

\section{Antecedentes da Lei de Benford}

O ser humano tende a acreditar que os números se distribuem de maneira uniforme na natureza. Por isso, ao manipular os valores de um banco de dados, uma pessoa leiga, em geral, não se preocupará com as frequências em que aparece o 1 ou 2 ou demais dígitos como primeiro, segundo ou último dígito de um número. Todavia, existe uma metodologia capaz de indicar a possibilidade de manipulação dos dados e, ao mesmo tempo, considerar a relevância financeira dos itens. Ela se baseia em uma regularidade empírica segundo a qual os números não se distribuem de maneira uniforme na natureza. Essa regularidade é conhecida como Lei de Benford.

Essa lei estabelece que as frequências dos primeiros dígitos dos valores em um banco de dados são decrescentes do 1 ao 9; o dígito 1 aparece em, aproximadamente, $30 \%$ dos itens, enquanto o 9 não atinge $5 \%$ desses valores. Essas frequências se aplicam a uma variedade de fontes de dados, incluindo contas de energia, endereços, preços de ações, valores populacionais, taxas de mortalidade, entre outras.

Estudos recentes (DuRstchl et al., 2004; CunHA, 2013; CunhA; BugARIN, 2014, 2015) sugerem que a Lei de Benford se aplica especialmente bem a planilhas de dados contábeis que envolvem o produto de preços por quantidades, como no caso de planilhas de obras públicas.

Com base nesse referencial, são medidas as frequências dos primeiros dígitos dos preços totais dos serviços da planilha orçamentária a ser analisada, estabelecendose uma comparação entre a Lei de Benford e os valores de fato encontrados. Sobre a diferença advinda dessa comparação, são aplicados testes estatísticos (Teste-Z, Qui-Quadrado e Média dos Desvios Absolutos) para mensurar se a magnitude dessa discrepância chega a representar, ou não, uma desconformidade com a Lei de Benford. A não conformidade pode ser vista como red flag, um sinal indicando quais valores possuem maiores indícios de terem sido manipulados, sendo os itens correspondentes naturais candidatos à auditoria. 
A ideia dessa distribuição surgiu quando, em 1881, Simon Newcomb, um astrônomo e matemático do século 19 , observou que as primeiras páginas das tábuas de logaritmos se apresentavam mais desgastadas do que as últimas, indicando que o valor usualmente mais acessado era o 1 , e que a frequência diminuía até o 9, contrariando o entendimento comum de uma distribuição uniforme da frequência desses dígitos (NEWCOMB, 1881). No entanto, fato só começou a ganhar importância mais de meio século depois, quando, em 1938, o físico Frank Benford incidentalmente chegou à mesma conclusão. Benford publicou artigo seminal, denominado The Law of Anomalous Numbers, em que utilizou dados coletados de diferentes tipos de fontes. Esses dados eram aleatórios, não possuíam relação entre si, e variavam desde números obtidos nas páginas principais dos jornais e todos os números de um tópico importante do Reader's Digest até tabelas matemáticas e constantes científicas. Seu trabalho analisou os primeiros dígitos dos dados coletados e mostrou que: $30,6 \%$ dos números possuíam 1 como primeiro dígito; o primeiro dígito 2 ocorria em $18,5 \%$ dos casos; e que, em contraste, somente $4,7 \%$ dos números possuíam como primeiro dígito o número 9 (BENFORD, 1938).

Um banco de dados tem maior chance de representar uma distribuição de Benford se os dados forem coletados de diferentes distribuições (HILL, 1995). Por outro lado, números atribuídos pela intervenção do homem, tais como números da Seguridade Social, códigos postais, contas bancárias, números telefônicos ou números fabricados por estudantes em experimentos geralmente não se conformam com a Lei de Benford (NIGRINI, 2000). Essa observação sugere que a Lei dos Números Anômalos pode ser usada para se detectar indícios de manipulação humana de dados.

Diversos estudos foram realizados adotando a hipótese de que dados fabricados são identificáveis mediante o desvio dos dígitos em relação à distribuição de Benford. Nigrini (1992, 2000, 2012) desenvolveu vários testes para mensurar a conformidade com a Lei de Benford, e, segundo divulgou o Wall Street Journal (BERTON, 1995), foram detectadas fraudes em sete companhias de Nova York pelo escritório da Procuradoria do Brooklyn usando esses testes. Como evidência, descobriu-se, nesse caso, que dados fraudulentos e aleatórios possuíam poucos valores começando com 1 e muitos números começando com 6 . Com base nesses sucessos, Nigrini foi chamado a dar consultoria a órgãos de arrecadação tributária de diversos países e a instalar os testes da Lei de Benford na maioria dos programas computacionais de detecção de fraude.

A Lei de Benford tem sido aplicada em campos cada vez mais diversos nos últimos 20 anos. Walter Mebane, um estatístico americano da Universidade de Michigan, estudou dados eleitorais de vários países, incluindo os Estados Unidos, 
Rússia e México. Em 2006, ele descobriu que a contagem dos votos tendia a seguir a Lei de Benford no segundo dígito (MEBANE, 2006). O pesquisador analisou os dados das eleições iranianas em 2009 e encontrou anomalias que indicavam fortemente a ocorrência de fraude na vitória do político Ahmadinejad (MEBANE, 2009). Mebane verificou que, nas cidades com poucos votos inválidos, os números de Ahmadinejad passavam longe da distribuição de Benford e que o candidato, nessas situações, possuía uma grande vantagem nos votos. Ainda na área eleitoral, Cho e Gaines (2007) analisam financiamento de campanhas, sugerindo que a Lei de Beford pode ser melhor aplicada quando se consideram contribuições in-kind (em espécie) aos comitês de campanha. Busta e Weinberg (1998) usaram a lei e uma metodologia baseada em redes neurais artificiais para distinguir entre dados financeiros normais e manipulados, mostrando que a metodologia consegue detectar bancos de dados manipulados em $68 \%$ dos casos e conclui corretamente que bancos de dados não contaminados estão limpos em $67 \%$ dos casos. Lu e Boritz (2005) usaram a lei para desenvolver um algoritmo para detecção de fraudes nas solicitações de restituição de seguros de saúde. No lado positivo, Giles (2007) verifica elevada conformidade com a Lei de Benford no caso de leilões de eBay².

No contexto de obras públicas, essa ferramenta começou a ser testada recentemente, tendo como marco inicial dissertação de mestrado, intitulada Aplicações da Lei Newcomb-Benford à auditoria de obras públicas (CUNHA, 2013). Foram testadas obras relevantes no contexto da Copa do Mundo de 2014, as quais haviam sido auditadas, em momento anterior, pelo Tribunal de Contas da União (TCU), e as análises efetuadas com base na Lei de Benford foram confrontadas com o sobrepreço detectado pelo TCU. Os serviços apontados por essa lei como tendo sofrido possível manipulação em seus preços corresponderam, em média, a $80 \%$ do sobrepreço identificado pelo tribunal.

Desse trabalho inicial, Cunha e Bugarin desenvolveram artigos para a Revista do TCU (Lei de Benford e auditoria de obras públicas: uma análise de sobrepreço na reforma do Maracanã, set/dez 2014); a revista Economics Bulletin (Benford's law for audit of public works: an analysis of overpricing in Maracanã soccer arena's renovation, maio 2015); a Revista NDJ (Lei de Benford e auditoria de obras públicas: uma análise de sobrepreço na construção da arena da Amazônia, ago 2015); a Revista Economia (Yokohama: a didactic note on the use of Benford's Law in public works auditing, with an application to the construction of Brazilian Amazon Arena 2014 World Cup soccer stadium, 2015); entre outros.

2 Outras aplicações, como, por exemplo, a evidência de que a Grécia manipulou os dados macroeconômicos informados ao Gabinete de Estatísticas da União Europeia (RaucH et al., 2011) encontram-se descritos em Cunha (2013). Hürlimann (2006) compila uma ampla bibliografia de artigos referentes à Lei de Benford de 1881 até 2006. 
Café (2015), em seu trabalho de conclusão de curso, O uso da Lei de Benford na auditoria de obras públicas: o caso do VLP, aplicou uma versão do algoritmo proposto por Bugarin e Cunha (2015) para detecção das rubricas com maiores evidências de sobrepreço na planilha contratual do Veículo Leve sobre Pneus (VLP) ou Expresso Sul, no Distrito Federal. O algoritmo apresentou resultados bastante favoráveis ao uso da Lei de Benford na auditoria. Foram revelados 73,40\% do superfaturamento apontado pelo Tribunal de Contas do Distrito Federal (TCDF) em apenas $38,17 \%$ do valor total da obra pública.

A Lei de Benford foi apresentada no VIII Seminário de Perícias de Engenharia da Polícia Federal por Azevedo Filho (2016): Fraude em licitações e a Lei de Benford - aplicação em perícias de engenharia civil do DPF. Esse trabalho consistiu na apresentação de uma detecção de fraude a uma licitação, que teve como finalidade elaborar Laudo Criminal de Engenharia após a deflagração da operação da Polícia Federal. Visando utilizar novas tecnologias de detecção de fraude em licitações e na formação de preços, aplicou-se a Lei de Benford verificando, assim, aderência a outros meios de prova, contribuindo para o fortalecimento do conjunto probatório e, ainda, indicando quais contratos, antes da deflagração de operações, poderiam ser mais críticos, para direcionar a colheita de provas mais robustas.

Visando oferecer aos profissionais de auditoria de obras públicas um roteiro didático e conciso para a aplicação dessa metodologia, detalhando o uso do algoritmo desenvolvido por Bugarin e Cunha (2015), Cunha, Bugarin e Portugal (2016) elaboraram a Cartilha Seleção de Amostra de Auditoria de Obras Públicas pela Lei de Benford, publicada e divulgada pelo Instituto Brasileiro de Obras Públicas no XVII Simpósio Nacional de Auditoria de Obras Públicas (Sinaop). Este artigo constitui mais uma contribuição para a avaliação da aplicabilidade da metodologia baseada na Lei de Benford para a seleção da amostra de auditoria de obras públicas.

\section{Testes da Lei de Benford baseados nas frequências dos dígitos ${ }^{3}$}

Os testes adotados neste estudo estão cuidadosamente caracterizados em Nigrini (2012). Eles serão apresentados, a seguir, de forma sintética.

\section{Teste dos Dois Primeiros Dígitos}

De acordo com a Lei de Benford, a frequência esperada da ocorrência de um número $D_{2}=d_{2}$ como segundo dígito em um conjunto de valores, dado que o primeiro dígito é $D_{1}=d_{1}$, é dada por:

\footnotetext{
${ }^{3}$ Esta seção mais técnica aproxima-se da descrição apresentada em Cunha e Bugarin (2014).
} 


$$
\operatorname{Prob}\left(D_{1} D_{2}=d_{1} d_{2}\right)=\log \left(1+\frac{1}{d_{1} d_{2}}\right)
$$

Sendo: $D_{1} D_{2}=$ dois primeiros dígitos e $d_{1} d_{2} \in\{10,11, \ldots, 99\}$

O teste compara cada frequência relativa observada de dois primeiros dígitos com a frequência esperada (Lei de Benford) por meio do Teste Z. Essa ferramenta estatística é calculada como mostrado a seguir, em que $i \in\{10,11, \ldots, 99\}$ representa a categoria de dois primeiros dígitos analisada; $n=90$ é o número de categorias de dois primeiros dígitos; $R F_{i}$ é a frequência relativa observada dos dois primeiros dígitos $i$; e $E R F_{i}$ é a frequência relativa esperada dos dois primeiros dígitos $i$.

$$
Z_{i}=\frac{\left|R F_{i}-E R F_{i}\right|-\left(\frac{1}{2 n}\right)}{\sqrt{\frac{E R F_{i}\left(1-E R F_{i}\right)}{n}}}
$$

O valor limite para esse teste, considerando o nível de significância de 5\%, é 1,96. Caso o resultado do Teste $Z$ para uma categoria de dois primeiros dígitos exceda esse valor, os itens da planilha que começarem com tais dígitos são fortes candidatos a uma inspeção mais cuidadosa.

Nigrini (2012) sugere três critérios para mensurar a conformidade com a Lei de Benford com base no Teste dos Dois Primeiros Dígitos. Primeiramente, se até cinco categorias de dois primeiros dígitos dentre as 90 existentes $\{10,11, \ldots, 99\}$ não se conformarem com a Lei, não existe forte evidência de manipulação.

Em segundo lugar, o Teste Qui-Quadrado também é calculado, conforme a seguir, em que $F_{i}$ é a frequência observada dos dois primeiros dígitos $i$ e $E F_{i}$ é a frequência esperada dos dois primeiros dígitos $i$.

$$
Q Q=\sum_{i=10}^{99} \frac{\left(F_{i}-E F_{i}\right)^{2}}{E F_{i}}
$$

O valor crítico para o nível de significância de $5 \%$ e 89 graus de liberdade é 112,02 . Caso o valor calculado exceda o valor crítico, a conformidade com a Lei de Benford deve ser rejeitada.

Finalmente, o Teste da Média dos Desvios Absolutos (MDA) é baseado nas diferenças absolutas entre as frequências relativas esperadas e observadas, de acordo com a fórmula a seguir:

$$
M D A=\frac{1}{n} \sum_{i=10}^{99}\left|R_{i-} E_{i}\right|
$$


Nigrini (2012) propôs o seguinte critério de conformidade para o MDA. Se o resultado for inferior a 0,0012, a conformidade é aproximada; se for superior a 0,0012, mas inferior a 0,0018, a conformidade é aceitável; se ele estiver no itervalo $(0,0018,0,0022)$, existe uma conformidade marginal aceitável; e, finalmente, se ele superar 0,0022, há uma desconformidade com a Lei de Benford.

\section{Teste da Soma}

Nigrini (2012), ao simular uma distribuição de Benford, descobriu que as somas dos números pertencentes a cada grupo de primeiros dígitos $10,11,12, \ldots$, 99 resultavam em valores aproximadamente iguais, ou seja, 1/90.

Todavia, o autor constatou que dados reais raramente se conformam a tal padrão, uma vez que eles possuem alguns valores muito altos ou muitas repetições de números de médio valor. Dessa forma ele desenvolveu o Teste da Soma, cuja utilidade é exatamente alertar sobre essas situações.

Apesar de possuir diferenças em relação à Curva $A B C$, a qual considera apenas os itens mais caros, o Teste da Soma também traz para a análise os serviços de valor relevante, mas, em vez de verificar a importância financeira do item individualmente, ele examina a importância do grupo de dois primeiros dígitos dentro do orçamento.

\section{Auditoria do TCU na obra de reforma do Aeroporto Internacional de Minas Gerais}

O TCU realizou auditoria na Empresa Brasileira de Infraestrutura Aeroportuária (Infraero), no período compreendido entre 20/1 e 4/2/2011, com o objetivo de avaliar o Edital de Licitação da Concorrência Internacional 010/2010 para contratação de empresa que iria executar a obra em tela.

A unidade técnica do TCU, após exame preliminar, identificou várias irregularidades no edital, entre elas sobrepreço de 47,35\%, em amostra de 48,56\% do orçamento, acima em $\mathrm{R} \$ 45.988 .657,61$ dos preços de referência.

A Infraero analisou os preços questionados pela Corte de Contas para os serviços constantes da parte $A$ (com valores mais significativos) da curva $A B C$ do orçamento base original no valor de $\mathrm{R} \$ 294.756 .117,22$. As alterações foram sintetizadas na Tabela 1, a seguir: 
Tabela 1 - Ajustes promovidos pela Infraero - preços questionados pelo TCU

\begin{tabular}{|c|c|c|c|}
\hline & Orçamento original & Novo orçamento & Observações \\
\hline Data-base & set/2010 & jan/2011 & \\
\hline Valor & $\mathrm{R} \$ 294.756 .117,22$ & $\mathrm{R} \$ 237.816 .280,91$ & \\
\hline $\begin{array}{l}\text { Valor da } \\
\text { amostra } \\
\text { analisada } \\
\text { pelo TCU }\end{array}$ & $\mathrm{R} \$ 143.119 .736,59$ & $\begin{array}{c}\mathrm{R} \$ 106.232 .055,48 \\
\left({ }^{*}\right)\end{array}$ & $\begin{array}{l}\left({ }^{*}\right) \text { Considerados os } \\
\text { serviços analisados na } \\
\text { instrução inicial, com } \\
\text { novos preços unitários e } \\
\text { quantitativos ajustados, } \\
\text { na nova data-base. }\end{array}$ \\
\hline $\begin{array}{c}\% \text { da amostra } \\
\text { analisada em } \\
\text { relação ao } \\
\text { orçamento }\end{array}$ & $48,56 \%$ & $44,67 \%$ & \\
\hline $\begin{array}{c}\text { Sobrepreço } \\
\text { absoluto }\end{array}$ & $\mathrm{R} \$ 45.988 .657,61$ & $\begin{array}{c}\mathrm{R} \$ 3.806 .501,89 \\
(* *)\end{array}$ & $\begin{array}{l}(* *) \text { Considerado o } \\
\text { reajuste do preço de } \\
\text { referência inicial para } \\
\text { a nova data-base, } \\
\text { utilizando os índices } \\
\text { adotados na minuta do } \\
\text { contrato. }\end{array}$ \\
\hline $\begin{array}{l}\text { Sobrepreço } \\
\text { relativo }\end{array}$ & $47,35 \%$ & $3,72 \%$ & \\
\hline
\end{tabular}

Fonte: Relatório do Ministro-Relator Valmir Campelo, referente ao Acórdão no 718/2011 - TCU-Plenário.

A entidade promoveu diversos ajustes nos preços dos serviços, reduzindo o orçamento da obra de $\mathrm{R} \$ 294.756 .117,22$ (a preços de setembro de 2010), para $\mathrm{R} \$ 237.816 .280,91$ (a preços de janeiro de 2011), no novo orçamento, o que representou um dispêndio a menor para a União de cerca de $\mathrm{R} \$ 57$ milhões. Porém, ao se aplicar a devida correção dos valores orçados em setembro de 2010, obteve-se o montante de $\mathrm{R} \$ 310.250 .216,07$ para o orçamento original. Assim, comparandose aquele orçamento e o novo, calculou-se uma economia para os cofres públicos de 72 milhões de reais ( $\mathrm{R} \$ 310.250 .216,07$ - R\$ 237.816.280,91), podendo-se considerar saneados os indícios de sobrepreço.

Contudo, a análise deste trabalho incidiu sobre o orçamento inicial, no valor de R\$ 294.756.117,22 (preços de set./2010), e adotou como parâmetro de mercado a redução nos preços promovida pela Infraero, que foi considerada suficiente para sanear os indícios de sobrepreço.

O TCU forneceu uma tabela detalhada ${ }^{4}$ que contém os serviços que sofreram as mais significativas reduções, num total de $\mathrm{R} \$ \mathbf{5 9 . 6 4 5 . 4 7 9 , 6 1}$, valor um pouco

\footnotetext{
${ }^{4}$ A Tabela correspondente não foi incluída neste trabalho por economia de espaço. Caso o leitor tenha interesse, favor solicitar aos autores.
} 
superior em relação ao total das reduções (cerca de $\mathrm{R} \$ 57$ milhões). Essa divergência ocorreu em função de alguns serviços não contemplados nessa tabela terem sofrido acréscimos, já que os ajustes promovidos pela Infraero também incluíram acréscimos em alguns itens. O somatório dos valores totais dos serviços analisados nessa tabela corresponde a $\mathrm{R} \$ 193.387 .999,24$ (65,61\% do valor total do orçamento).

Cabe ressaltar que esses ajustes incidiram tanto nos preços unitários, quanto nas quantidades dos serviços. Como a análise em tela contempla os preços totais, que são as quantidades multiplicadas pelos preços unitários, qualquer sinalização da Lei de Benford em relação a algum item específico pode se referir a indícios de impropriedades tanto no preço quanto na quantidade.

\section{Metodologia adotada para seleção da amostra de auditoria}

A metodologia adotada neste trabalho se baseia no algoritmo proposto por Bugarin e Cunha (2015) e detalhado de forma pormenorizada em Cunha, Bugarin e Portugal (2016). O principal objetivo do algoritmo é selecionar uma amostra que contenha as observações que possuam a maior probabilidade de terem sido manipuladas, de acordo com os testes inspirados na Lei de Benford.

Uma limitação dessa metodologia é a exigência de que a planilha orçamentária contenha, no mínimo, 800 itens, já que, como os dados serão divididos em 90 grupos nos testes da Lei de Benford, um orçamento com poucos itens pode apresentar uma falsa desconformidade com essa lei.

Primeiramente, definem-se os parâmetros básicos e é selecionada a primeira amostra de auditoria. Se o custo total da amostra já se aproximar do valor padrão estipulado inicialmente, então essa será a amostra final. Caso o valor total da amostra seja muito alto ou muito baixo, deve-se readequar, em primeiro lugar, os critérios de seleção do Teste da Soma, para depois, se necessário, alterar o nível de confiança do Teste dos Dois Primeiros Dígitos. Nenhuma outra flexibilização deve ser permitida. Se a amostra final ainda assim continuar com o valor muito baixo, então o algoritmo não é capaz de selecionar itens suficientes com base exclusivamente no critério da Lei de Benford. Nesse caso, a amostra pode ser complementada com outro critério, tal como o custo dos serviços, da mesma forma adotada na metodologia da Curva ABC. A Tabela 2, a seguir, detalha o algoritmo. 
Tabela 2 - Etapas de aplicação do algoritmo

\begin{tabular}{|c|c|}
\hline Etapa & Ação \\
\hline \multirow[t]{2}{*}{ 19. Etapa } & Definição dos parâmetros iniciais \\
\hline & $\begin{array}{l}\text { Valor total do orçamento }=\mathrm{T} \\
\text { Variável a ser analisada: custo/preço total } \\
\% \text { do orçamento a ser examinado }=80 \% \\
\text { Nível de significância adotado no Teste dos Dois Primeiros Dígitos }=5 \% \\
\text { Limite mínimo para o resultado do Teste da Soma (coluna diferença) }=0,011 \\
\text { Ajustes que podem ser realizados no limite mínimo (Teste da Soma) }=+/-25 \% \\
\text { (10 ajuste; } 0,01375 / 0,00825) ;+/-50 \% \text { ( } 2 \text { o ajuste; } 0,0165 / 0,0055) \text { e }+/-75 \% \text { (3 } \\
\text { ajuste; } 0,01975 / 0,00275)\end{array}$ \\
\hline \multirow[t]{2}{*}{ 2a Etapa } & Teste dos Dois Primeiros Dígitos \\
\hline & $\begin{array}{l}\text { (i) Aplicar o Teste dos Dois Primeiros Dígitos utilizando o critério de significância } \\
\text { de } 5 \% \text {. Selecionar as categorias de dois primeiros dígitos que ultrapassarem o } \\
\text { valor crítico para o Teste } Z(1,96) \text {. } \\
\text { (ii) Aplicar o Teste dos Dois Primeiros Dígitos utilizando o critério de significância } \\
\text { de } 10 \% \text { (aumentar o tamanho da amostra). Selecionar as categorias de dois } \\
\text { primeiros dígitos que ultrapassarem o valor crítico para o Teste } Z(1,64) \text {. }\end{array}$ \\
\hline \multirow[t]{2}{*}{ 3a Etapa } & Teste da Soma \\
\hline & $\begin{array}{l}\text { (i) Aplicar o Teste da Soma e selecionar todas as categorias de dois primeiros } \\
\text { dígitos cujo resultado para a coluna diferença tenha ultrapassado } 0,011 \text {. } \\
\text { (ii) Aplicar o Teste da Soma e selecionar todas as categorias de dois primeiros } \\
\text { dígitos cujo resultado para a coluna diferença tenha ultrapassado } 0,00825 \\
\text { ( } 1 \text { o ajuste), } 0,0055 \text { ( } 2 \text { o ajuste) ou } 0,00275 \text { ( } 3 \text { - ajuste; aumentar o tamanho da } \\
\text { amostra). } \\
\text { (iii) Aplicar o Teste da Soma e selecionar todas as categorias de dois primeiros } \\
\text { dígitos cujo resultado para a coluna diferença tenha ultrapassado } 0,01375 \text { (1ㅇ } \\
\text { ajuste), } 0,0165 \text { ( } 2 \text { - ajuste) ou } 0,0175 \text { ( } 3 \text { o ajuste; diminuir o tamanho da amostra). }\end{array}$ \\
\hline \multirow[t]{2}{*}{ 4a Etapa } & Confronto entre o Teste dos Dois Primeiros Dígitos e o Teste da Soma \\
\hline & $\begin{array}{l}\text { Selecionar as categorias de dígitos detectadas como críticas no Teste dos Dois } \\
\text { Primeiros Dígitos e no Teste da Soma. Realizar um confronto entre os testes para } \\
\text { confirmar a criticidade dos dois primeiros dígitos selecionados, de modo a obter } \\
\text { a amostra a ser auditada. }\end{array}$ \\
\hline \multirow[t]{2}{*}{ 5a Etapa } & Valor da amostra selecionada \\
\hline & Calcular o valor total da amostra na planilha orçamentária. \\
\hline \multirow[t]{2}{*}{ 6a Etapa } & Comparação da amostra com o valor total do orçamento \\
\hline & $\begin{array}{l}\text { Verificar quanto a amostra selecionada representa em termos percentuais em } \\
\text { relação ao valor total do orçamento. } \\
\text { Se amostra }-90 \% \text { (+/- } 5 \% \text { ), então ir para a 7ạ Etapa. } \\
\text { Se amostra }<80 \% \text {, então reduzir o limiar do Teste da Soma em } 25 \%, 50 \% \text { até } \\
75 \% \text { e ir par a } 3 \text { a Etapa (ii). } \\
\text { Se amostra }>80 \% \text {, então aumentar o limiar do Teste da Soma em } 25 \%, 50 \% \text { até } \\
75 \% \text { e ir para a } 3 \text { a Etapa (iii). } \\
\text { Como último recurso, se a amostra continuar muito inferior a } 80 \% \text {, aumentar o } \\
\text { nível de significância para } 10 \% \text { no Teste dos Dois Primeiros Dígitos e retornar à } \\
\text { 2a Etapa (ii). }\end{array}$ \\
\hline \multirow[t]{2}{*}{ 7a Etapa } & Amostra de auditoria \\
\hline & $\begin{array}{l}\text { Se for obtida uma amostra próxima ao percentual desejado em relação ao valor } \\
\text { do orçamento }(80 \%) \text {, tem-se a amostra final. }\end{array}$ \\
\hline \multirow[t]{2}{*}{ 8a Etapa } & Complementação da amostra adotando os critérios da Curva ABC \\
\hline & $\begin{array}{l}\text { Caso a metodologia baseada na Lei de Benford não seja capaz de identificar um } \\
\text { número de categorias de dois primeiros dígitos suficientes para que os custos } \\
\text { correspondentes se aproximem do percentual desejado, complementar a } \\
\text { amostra adotando os critérios da Curva } A B C \text {. }\end{array}$ \\
\hline \multicolumn{2}{|c|}{$\begin{array}{l}\text { Legenda: } \\
\text { (i) Aplicação dos parâmetros básicos. } \\
\text { (ii) Aumento do tamanho da amostra de auditoria. } \\
\text { (iii) Redução do tamanho da amostra de auditoria. } \\
\text { Fonte: Cunha, Bugarin e Portugal (2016). }\end{array}$} \\
\hline
\end{tabular}


1aㅡ Etapa: definição dos parâmetros iniciais

O algoritmo será aplicado ao orçamento da obra de reforma do Aeroporto Internacional Tancredo Neves (MG).

a) Qual é o valor total do orçamento?

O valor do orçamento é $\mathrm{R} \$ 294.756 .117,22$ (preços de set./2010) com a taxa de Benefícios e Despesas Indiretas (BDI) diferenciada para serviços e equipamentos $(28,87 \%$ e $12,70 \%)$ inclusa.

Caso a taxa de BDI fosse única, sua inclusão ou não nesta análise não alteraria as frequências dos primeiros dígitos do banco de dados. Segundo Pinkham (1961), as frequências dos dígitos de uma distribuição de Benford não variam quando os números são multiplicados por uma constante. Como essa taxa é diferenciada para serviços e equipamentos, deve ser obrigatoriamente inserida nos dados.

b) Qual variável será analisada: quantidade, custo/preço unitário ou custo/ preço total?

Neste exemplo, serão testados os preços totais (quantidades $\mathrm{x}$ preços unitários). Cabe ressaltar que os itens idênticos da planilha orçamentária não devem ser agrupados, como ocorre na metodologia da Curva ABC.

c) Qual é o percentual do valor total do orçamento que deve ser examinado?

Ele será definido aqui em $80 \%$ para preservar o padrão adotado na metodologia da Curva $A B C$, mas outros padrões também podem ser utilizados. Tolera-se uma variação de +/- $5 \%$ em cima desse percentual.

d) Qual é o nível de significância adotado no Teste dos Dois Primeiros Dígitos?

De acordo com Nigrini (2012), ele é inicialmente fixado em $5 \%$.

e) Qual é o limite mínimo do resultado do Teste da Soma (coluna diferença), acima do qual os dois primeiros dígitos são considerados críticos?

Seguindo a proposta desta cartilha, ele é inicialmente fixado em 0,011, que corresponde a $100 \%$ do valor de referência da Lei de Benford para esse teste.

f) Qual ajuste deverá ser realizado no limite mínimo do Teste da Soma $(0,011)$, para diminuir ou aumentar o rigor do teste, caso necessário?

Inicialmente, ele é fixado em $25 \%$, podendo ser estendido para $50 \%$ em um segundo ajuste, até o limite de $75 \%$ em um terceiro ajuste, não se tolerando mais flexibilizações.

\section{2a Etapa: Teste dos Dois Primeiros Dígitos}

O Teste dos Dois Primeiros Dígitos é aplicado adotando o nível de significância de $5 \%$ para os testes estatísticos.

Devem ser selecionadas as categorias de dois primeiros dígitos cujos resultados para o Teste $Z$ superaram o valor crítico $(1,96)$ para o nível de significância de $5 \%$. 
Cabe informar que, apesar de a planilha possuir 2095 serviços, analisaram-se 2081 itens para os testes, já que foram excluídos os valores menores do que 10, os quais não possuíam segundo dígito.

Os resultados encontram-se reportados na Tabela 3, em que: Díg. se referem aos dois primeiros dígitos dos valores; $\mathbf{C}$ são as contagens desses dígitos no banco de dados; Freq. são as frequências relativas com que os dígitos aparecem na planilha; LB são as frequências padrão da Lei de Benford; Dif. são as diferenças entre as colunas Freq. e LB; Teste $\mathbf{Z}$ se refere aos resultados do Teste Z; $\mathbf{Q Q}$ se relaciona ao cálculo estatístico intermediário do Teste Qui-Quadrado; e MDA corresponde ao cálculo estatístico intermediário da Média dos Desvios Absolutos.

Segundo a Tabela 3, com base no Teste Z, foram apontadas desconformidades dos dois primeiros dígitos 21, 22, 23, 28, 39, 53, 59, 61, 72, 76, 79, 82 e 83 em relação à Lei de Benford. Essas treze categorias de dígitos que excederam o limite de 1,96 do Teste $Z$ superam os cincos picos permitidos por Nigrini (2012), indicando uma desconformidade dos dados. Cabe ressaltar que alguns dos picos correspondem a categorias de dígitos que apareceram com muita frequência na planilha enquanto outras se referem a dígitos que se repetiram muito pouco. Naturalmente, é esperado que aqueles que tiveram uma frequência alta sejam os grandes candidatos a terem sofrido manipulação.

Tabela 3 - Categorias de dígitos selecionadas no Teste dos Dois Primeiros Dígitos

\begin{tabular}{|c|c|c|c|c|c|c|c|c|c|c|c|c|c|c|c|}
\hline Díg. & C & Freq. & LB & Dif. & Teste-Z & QQ & MDA & Díg. & C & Freq. & LB & Dif. & Teste-Z & $\mathrm{QQ}$ & MDA \\
\hline 10 & 86 & 0,041 & 0,041 & 0,000 & 0,015 & 0,000 & 0,000 & 55 & 18 & 0,009 & 0,008 & 0,001 & 0,427 & 0,181 & 0,001 \\
\hline 11 & 94 & 0,045 & 0,038 & 0,007 & 1,766 & 3,001 & 0,007 & 56 & 16 & 0,008 & 0,008 & 0,000 & 0,001 & 0,000 & 0,000 \\
\hline 12 & 74 & 0,036 & 0,035 & 0,001 & 0,199 & 0,038 & 0,001 & 57 & 17 & 0,008 & 0,008 & 0,001 & 0,325 & 0,105 & 0,001 \\
\hline 13 & 57 & 0,027 & 0,032 & $-0,005$ & 1,239 & 1,486 & 0,005 & 58 & 12 & 0,006 & 0,007 & $-0,002$ & 0,881 & 0,770 & 0,002 \\
\hline 14 & 69 & 0,033 & 0,030 & 0,003 & 0,855 & 0,708 & 0,003 & 59 & 32 & 0,015 & 0,007 & 0,008 & 4,329 & 18,604 & 0,008 \\
\hline 15 & 56 & 0,027 & 0,028 & $-0,001$ & 0,309 & 0,093 & 0,001 & 60 & 10 & 0,005 & 0,007 & $-0,002$ & 1,282 & 1,633 & 0,002 \\
\hline 16 & 49 & 0,024 & 0,026 & $-0,003$ & 0,793 & 0,612 & 0,003 & 61 & 28 & 0,013 & 0,007 & 0,006 & 3,483 & 12,045 & 0,006 \\
\hline 17 & 60 & 0,029 & 0,025 & 0,004 & 1,175 & 1,347 & 0,004 & 62 & 15 & 0,007 & 0,007 & 0,000 & 0,142 & 0,020 & 0,000 \\
\hline 18 & 52 & 0,025 & 0,023 & 0,002 & 0,454 & 0,201 & 0,002 & 63 & 15 & 0,007 & 0,007 & 0,000 & 0,204 & 0,041 & 0,000 \\
\hline 19 & 44 & 0,021 & 0,022 & $-0,001$ & 0,350 & 0,120 & 0,001 & 64 & 17 & 0,008 & 0,007 & 0,001 & 0,801 & 0,637 & 0,001 \\
\hline 20 & 34 & 0,016 & 0,021 & $-0,005$ & 1,537 & 2,311 & 0,005 & 65 & 11 & 0,005 & 0,007 & $-0,001$ & 0,756 & 0,567 & 0,001 \\
\hline 21 & 55 & 0,026 & 0,020 & 0,006 & 2,019 & 3,993 & 0,006 & 66 & 7 & 0,003 & 0,007 & $-0,003$ & 1,794 & 3,196 & 0,003 \\
\hline 22 & 27 & 0,013 & 0,019 & $-0,006$ & 2,099 & 4,320 & 0,006 & 67 & 13 & 0,006 & 0,006 & 0,000 & 0,107 & 0,011 & 0,000 \\
\hline 23 & 51 & 0,025 & 0,018 & 0,006 & 2,040 & 4,086 & 0,006 & 68 & 14 & 0,007 & 0,006 & 0,000 & 0,223 & 0,049 & 0,000 \\
\hline 24 & 37 & 0,018 & 0,018 & 0,000 & 0,018 & 0,000 & 0,000 & 69 & 12 & 0,006 & 0,006 & 0,000 & 0,279 & 0,078 & 0,000 \\
\hline 25 & 29 & 0,014 & 0,017 & $-0,003$ & 1,092 & 1,172 & 0,003 & 70 & 12 & 0,006 & 0,006 & 0,000 & 0,230 & 0,052 & 0,000 \\
\hline 26 & 27 & 0,013 & 0,016 & $-0,003$ & 1,227 & 1,481 & 0,003 & 71 & 12 & 0,006 & 0,006 & 0,000 & 0,181 & 0,032 & 0,000 \\
\hline 27 & 39 & 0,019 & 0,016 & 0,003 & 1,078 & 1,144 & 0,003 & 72 & 26 & 0,012 & 0,006 & 0,007 & 3,845 & 14,694 & 0,007 \\
\hline 28 & 20 & 0,010 & 0,015 & $-0,006$ & 2,096 & 4,327 & 0,006 & 73 & 11 & 0,005 & 0,006 & $-0,001$ & 0,371 & 0,137 & 0,001 \\
\hline 29 & 28 & 0,013 & 0,015 & $-0,001$ & 0,480 & 0,227 & 0,001 & 74 & 7 & 0,003 & 0,006 & $-0,002$ & 1,478 & 2,170 & 0,002 \\
\hline 30 & 31 & 0,015 & 0,014 & 0,001 & 0,253 & 0,063 & 0,001 & 75 & 11 & 0,005 & 0,006 & 0,000 & 0,281 & 0,079 & 0,000 \\
\hline 31 & 37 & 0,018 & 0,014 & 0,004 & 1,562 & 2,405 & 0,004 & 76 & 22 & 0,011 & 0,006 & 0,005 & 2,972 & 8,782 & 0,005 \\
\hline 32 & 20 & 0,010 & 0,013 & $-0,004$ & 1,491 & 2,194 & 0,004 & 77 & 7 & 0,003 & 0,006 & $-0,002$ & 1,369 & 1,863 & 0,002 \\
\hline 33 & 23 & 0,011 & 0,013 & $-0,002$ & 0,771 & 0,587 & 0,002 & 78 & 16 & 0,008 & 0,006 & 0,002 & 1,326 & 1,749 & 0,002 \\
\hline 34 & 20 & 0,010 & 0,013 & $-0,003$ & 1,219 & 1,466 & 0,003 & 79 & 24 & 0,012 & 0,005 & 0,006 & 3,757 & 14,036 & 0,006 \\
\hline 35 & 31 & 0,015 & 0,012 & 0,003 & 1,105 & 1,206 & 0,003 & 80 & 16 & 0,008 & 0,005 & 0,002 & 1,428 & 2,029 & 0,002 \\
\hline 36 & 17 & 0,008 & 0,012 & $-0,004$ & 1,569 & 2,433 & 0,004 & 81 & 12 & 0,006 & 0,005 & 0,000 & 0,274 & 0,075 & 0,000 \\
\hline 37 & 20 & 0,010 & 0,012 & $-0,002$ & 0,840 & 0,698 & 0,002 & 82 & 4 & 0,002 & 0,005 & $-0,003$ & 2,107 & 4,415 & 0,003 \\
\hline 38 & 19 & 0,009 & 0,011 & $-0,002$ & 0,929 & 0,853 & 0,002 & 83 & 4 & 0,002 & 0,005 & $-0,003$ & 2,080 & 4,302 & 0,003 \\
\hline 39 & 34 & 0,016 & 0,011 & 0,005 & 2,337 & 5,403 & 0,005 & 84 & 11 & 0,005 & 0,005 & 0,000 & 0,093 & 0,009 & 0,000 \\
\hline 40 & 26 & 0,012 & 0,011 & 0,002 & 0,784 & 0,608 & 0,002 & 85 & 8 & 0,004 & 0,005 & $-0,001$ & 0,793 & 0,625 & 0,001 \\
\hline 41 & 24 & 0,012 & 0,010 & 0,001 & 0,479 & 0,227 & 0,001 & 86 & 6 & 0,003 & 0,005 & $-0,002$ & 1,380 & 1,894 & 0,002 \\
\hline
\end{tabular}




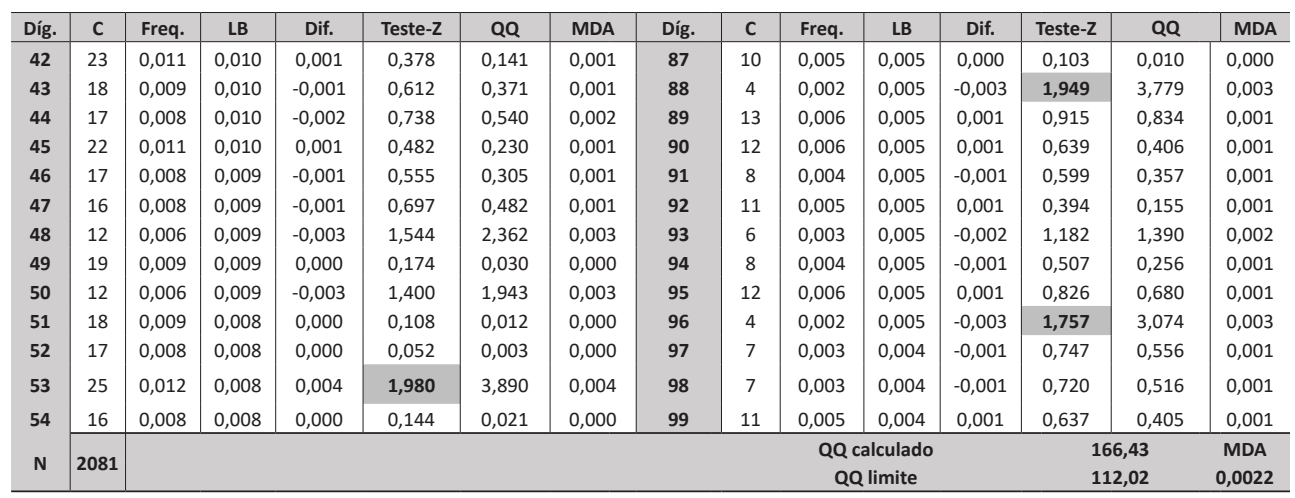

Fonte: Elaboração própria, 2017.

O resultado do Teste Qui-Quadrado, que consiste no somatório da coluna QQ, foi 166,43 , o qual ultrapassa o valor crítico de 112,02 para 89 graus de liberdade e $5 \%$ de significância estatística. Portanto, rejeita-se a hipótese nula de que os dados apresentam conformidade em relação à Lei de Benford, sugerindo, novamente, uma desconformidade.

O último teste aplicado foi o MDA, cujo resultado corresponde ao somatório da coluna MDA. O valor encontrado foi 0,022 , o qual estava na fronteira da conformidade marginal aceitável com a não conformidade (NIGRINI, 2012).

Considerando todos os testes aplicados para os dois primeiros dígitos, pode-se verificar que a planilha orçamentária do Aeroporto Internacional Tancredo Neves apresentou uma não conformidade no Teste Z e no Teste Qui-Quadrado, e uma conformidade marginal no MDA.

3a Etapa: Teste da Soma

O Teste da Soma é aplicado e são selecionadas todas as categorias de dois primeiros dígitos cujos valores para a coluna diferença sejam iguais ou superiores a 0,011. Os resultados estão ilustrados na Tabela 4.

$\mathrm{Na}$ Tabela 4, a 1a e 6a colunas se referem aos dois primeiros dígitos; as 2a e 7ạ colunas correspondem à soma dos itens que possuem os dois primeiros dígitos apontados nas 1a e 6a colunas, respectivamente; as 3 a e 8 a colunas mostram as proporções das somas calculadas nas 2 a e 7a colunas, respectivamente, em relação ao somatório de todos os custos unitários da planilha; as 4ạ e 9a colunas apresentam as frequências padrão da Lei de Benford; e as 5a e 10ạ colunas trazem a diferença entre as proporções das somas e as frequências da Lei de Benford.

Conforme se observa na Tabela 4, houve picos nos dois primeiros dígitos 10, 11 , $15,20,22,28,29,42,62,71$ e 79 . Chama atenção a proporção encontrada para a categoria 15 , que representou $12,2 \%$ do somatório dos preços totais. Esse teste sugere uma grande desconformidade com a Lei de Benford. 
Tabela 4 - Teste da Soma para os preços totais da reforma do Aeroporto Internacional Tancredo Neves. Número de observações $(\mathrm{N})=\mathbf{2 . 0 8 1}$

\begin{tabular}{|c|c|c|c|c|c|c|c|c|c|}
\hline Dígito & Soma & Prop. & Benford & Diferença & Dígito & Soma & Prop. & Benford & Diferença \\
\hline 10 & $17.954 .753,01$ & 0,061 & 0,011 & 0,050 & 55 & $1.888 .615,98$ & 0,006 & 0,011 & $-0,005$ \\
\hline 11 & $11.400 .040,89$ & 0,039 & 0,011 & 0,028 & 56 & $310.143,47$ & 0,001 & 0,011 & $-0,010$ \\
\hline 12 & $5.938 .715,62$ & 0,020 & 0,011 & 0,009 & 57 & $1.882 .596,99$ & 0,006 & 0,011 & $-0,005$ \\
\hline 13 & $4.243 .391,88$ & 0,014 & 0,011 & 0,003 & 58 & $260.126,02$ & 0,001 & 0,011 & $-0,010$ \\
\hline 14 & $4.720 .576,11$ & 0,016 & 0,011 & 0,005 & 59 & $1.092 .586,79$ & 0,004 & 0,011 & $-0,007$ \\
\hline 15 & $35.997 .509,51$ & 0,122 & 0,011 & 0,111 & 60 & $1.893 .759,02$ & 0,006 & 0,011 & $-0,005$ \\
\hline 16 & $3.553 .475,32$ & 0,012 & 0,011 & 0,001 & 61 & $1.262 .767,79$ & 0,004 & 0,011 & $-0,007$ \\
\hline 17 & $1.629 .096,81$ & 0,006 & 0,011 & $-0,005$ & 62 & $12.759 .513,57$ & 0,043 & 0,011 & 0,032 \\
\hline 18 & $3.367 .756,48$ & 0,011 & 0,011 & 0,000 & 63 & $863.161,54$ & 0,003 & 0,011 & $-0,008$ \\
\hline 19 & $3.490 .624,80$ & 0,012 & 0,011 & 0,001 & 64 & $1.528 .770,59$ & 0,005 & 0,011 & $-0,006$ \\
\hline 20 & $26.641 .371,16$ & 0,090 & 0,011 & 0,079 & 65 & $802.303,92$ & 0,003 & 0,011 & $-0,008$ \\
\hline 21 & $5.870 .070,91$ & 0,020 & 0,011 & 0,009 & 66 & $690.425,74$ & 0,002 & 0,011 & $-0,009$ \\
\hline 22 & $25.564 .236,26$ & 0,087 & 0,011 & 0,076 & 67 & $1.036 .886,31$ & 0,004 & 0,011 & $-0,007$ \\
\hline 23 & $4.510 .248,28$ & 0,015 & 0,011 & 0,004 & 68 & $2.308 .601,84$ & 0,008 & 0,011 & $-0,003$ \\
\hline 24 & $1.447 .339,91$ & 0,005 & 0,011 & $-0,006$ & 69 & $451.734,36$ & 0,002 & 0,011 & $-0,009$ \\
\hline 25 & $3.974 .026,92$ & 0,013 & 0,011 & 0,002 & 70 & $870.025,04$ & 0,003 & 0,011 & $-0,008$ \\
\hline 26 & $2.249 .661,40$ & 0,008 & 0,011 & $-0,003$ & 71 & $8.656 .078,00$ & 0,029 & 0,011 & 0,018 \\
\hline 27 & $4.033 .330,96$ & 0,014 & 0,011 & 0,003 & 72 & $440.598,74$ & 0,001 & 0,011 & $-0,010$ \\
\hline 28 & $6.801 .977,59$ & 0,023 & 0,011 & 0,012 & 73 & $1.666 .527,66$ & 0,006 & 0,011 & $-0,005$ \\
\hline 29 & 7.927.551,81 & 0,027 & 0,011 & 0,016 & 74 & $171.795,82$ & 0,001 & 0,011 & $-0,010$ \\
\hline 30 & $1.938 .406,51$ & 0,007 & 0,011 & $-0,004$ & 75 & $1.100 .183,43$ & 0,004 & 0,011 & $-0,007$ \\
\hline 31 & $4.603 .245,66$ & 0,016 & 0,011 & 0,005 & 76 & $463.804,62$ & 0,002 & 0,011 & $-0,009$ \\
\hline 32 & 697.997,98 & 0,002 & 0,011 & $-0,009$ & 77 & $193.020,58$ & 0,001 & 0,011 & $-0,010$ \\
\hline 33 & $1.302 .224,81$ & 0,004 & 0,011 & $-0,007$ & 78 & $1.095 .882,16$ & 0,004 & 0,011 & $-0,007$ \\
\hline 34 & $1.028 .072,56$ & 0,003 & 0,011 & $-0,008$ & 79 & $9.175 .340,37$ & 0,031 & 0,011 & 0,020 \\
\hline 35 & $1.226 .748,25$ & 0,004 & 0,011 & $-0,007$ & 80 & $2.710 .907,52$ & 0,009 & 0,011 & $-0,002$ \\
\hline 36 & $2.033 .289,83$ & 0,007 & 0,011 & $-0,004$ & 81 & $1.918 .927,42$ & 0,007 & 0,011 & $-0,004$ \\
\hline 37 & $1.511 .731,05$ & 0,005 & 0,011 & $-0,006$ & 82 & $100.098,87$ & 0,000 & 0,011 & $-0,011$ \\
\hline 38 & $930.439,46$ & 0,003 & 0,011 & $-0,008$ & 83 & $108.689,00$ & 0,000 & 0,011 & $-0,011$ \\
\hline 39 & $1.630 .744,74$ & 0,006 & 0,011 & $-0,005$ & 84 & $289.028,83$ & 0,001 & 0,011 & $-0,010$ \\
\hline 40 & $2.166 .410,49$ & 0,007 & 0,011 & $-0,004$ & 85 & $1.367 .807,94$ & 0,005 & 0,011 & $-0,006$ \\
\hline 41 & $2.389 .527,92$ & 0,008 & 0,011 & $-0,003$ & 86 & $355.554,33$ & 0,001 & 0,011 & $-0,010$ \\
\hline 42 & $6.391 .540,45$ & 0,022 & 0,011 & 0,011 & 87 & $158.109,72$ & 0,001 & 0,011 & $-0,010$ \\
\hline 43 & $1.049 .357,90$ & 0,004 & 0,011 & $-0,007$ & 88 & $114.843,38$ & 0,000 & 0,011 & $-0,011$ \\
\hline 44 & $872.734,32$ & 0,003 & 0,011 & $-0,008$ & 89 & $1.929 .961,63$ & 0,007 & 0,011 & $-0,004$ \\
\hline 45 & $1.304 .774,75$ & 0,004 & 0,011 & $-0,007$ & 90 & $2.833 .069,06$ & 0,010 & 0,011 & $-0,001$ \\
\hline 46 & $1.525 .280,84$ & 0,005 & 0,011 & $-0,006$ & 91 & 1.051.317,99 & 0,004 & 0,011 & $-0,007$ \\
\hline 47 & $320.493,81$ & 0,001 & 0,011 & $-0,010$ & 92 & $258.909,99$ & 0,001 & 0,011 & $-0,010$ \\
\hline 48 & $1.190 .469,15$ & 0,004 & 0,011 & $-0,007$ & 93 & $29.977,90$ & 0,000 & 0,011 & $-0,011$ \\
\hline 49 & $927.444,30$ & 0,003 & 0,011 & $-0,008$ & 94 & $1.151 .931,70$ & 0,004 & 0,011 & $-0,007$ \\
\hline 50 & $735.554,59$ & 0,002 & 0,011 & $-0,009$ & 95 & $1.277 .598,83$ & 0,004 & 0,011 & $-0,007$ \\
\hline 51 & $640.979,14$ & 0,002 & 0,011 & $-0,009$ & 96 & $204.277,00$ & 0,001 & 0,011 & $-0,010$ \\
\hline 52 & $1.957 .553,15$ & 0,007 & 0,011 & $-0,004$ & 97 & $226.142,68$ & 0,001 & 0,011 & $-0,010$ \\
\hline 53 & $1.137 .267,64$ & 0,004 & 0,011 & $-0,007$ & 98 & $2.010 .965,17$ & 0,007 & 0,011 & $-0,004$ \\
\hline 54 & $838.616,58$ & 0,003 & 0,011 & $-0,008$ & 99 & 2.131.029,61 & 0,007 & 0,011 & $-0,004$ \\
\hline \multicolumn{5}{|c|}{ SOMA TOTAL } & \multicolumn{5}{|c|}{$294.761 .060,43$} \\
\hline
\end{tabular}

Fonte: Elaboração própria, 2017.

\section{4a Etapa: confronto entre o Teste dos Dois Primeiros Dígitos e o Teste da Soma}

Devem ser selecionadas as categorias de dígitos detectadas como críticas no Teste dos Dois Primeiros Dígitos e no Teste da Soma. É realizado um confronto (Tabela 5) entre os testes para confirmar a criticidade dos dois primeiros dígitos selecionados, comparando o número de vezes em que eles se repetem na planilha 
(frequência), dada pelo Teste dos Dois Primeiros Dígitos, com a relevância financeira trazida pelo Teste da Soma (proporção). Os níveis de criticidade são mensurados de acordo com os critérios a seguir:

Quando uma categoria de dois primeiros dígitos aparece como crítica em ambos os testes - neste exemplo a 79 -, esse é o maior nível de criticidade identificado por essa metodologia, e, portanto, os serviços correspondentes devem ser priorizados na análise.

Todos os grupos de dígitos detectados pelo Teste da Soma já entram automaticamente como críticos, em função de sua relevância financeira.

Algumas categorias de dígitos, apesar de terem sido detectadas pelo Teste dos Dois Primeiros Dígitos, possuem baixa relevância financeira, como no caso do exemplo da Tabela 5 no que se refere às categorias 72, 76, 82 e 83. Dessa forma, não compensa incluir esses itens na amostra de auditoria, quando são examinados os preços totais do orçamento. Ademais, como se pode observar, os grupos 82 e 83 foram identificados pelo Teste $Z$ em função de sua baixa frequência na planilha $(0,002)$, ou seja, eles foram considerados irrelevantes em ambos os testes.

\section{Tabela 5 - Confronto entre o Teste dos Dois Primeiros Dígitos e o Teste da Soma}

\begin{tabular}{|c|c|c|c|c|c|c|c|}
\hline Dígitos & $\begin{array}{c}\text { Frequência } \\
\text { (Teste Dois } \\
\text { Primeiros } \\
\text { Dígitos). }\end{array}$ & $\begin{array}{c}\text { Proporção } \\
\text { (Teste da } \\
\text { Soma) }\end{array}$ & Crítico? & Dígitos & $\begin{array}{c}\text { Frequência } \\
\text { (Teste Dois } \\
\text { Primeiros } \\
\text { Dígitos) }\end{array}$ & $\begin{array}{c}\text { Proporção } \\
\text { (Teste da } \\
\text { Soma) }\end{array}$ & Crítico? \\
\hline 10 & 0,041 & 0,061 & Sim & 53 & 0,012 & 0,004 & Sim \\
\hline 11 & 0,045 & 0,039 & Sim & 59 & 0,015 & 0,004 & Sim \\
\hline 15 & 0,027 & 0,122 & Sim & 61 & 0,013 & 0,004 & Sim \\
\hline 20 & 0,016 & 0,090 & Sim & 62 & 0,007 & 0,043 & Sim \\
\hline 21 & 0,026 & 0,020 & Sim & 71 & 0,006 & 0,029 & Sim \\
\hline 22 & 0,013 & 0,087 & Sim & 72 & 0,012 & 0,001 & Não \\
\hline 23 & 0,025 & 0,015 & Sim & 76 & 0,011 & 0,002 & Não \\
\hline 28 & 0,010 & 0,023 & Sim & 79 & 0,012 & 0,031 & Sim \\
\hline 29 & 0,013 & 0,027 & Sim & 82 & 0,002 & 0,000 & Não \\
\hline 39 & 0,016 & 0,006 & Sim & 83 & 0,002 & 0,000 & Não \\
\hline 42 & 0,011 & 0,022 & Sim & & & & \\
\hline
\end{tabular}

Fonte: Elaboração própria, 2017.

$\mathrm{Na}$ Tabela 5, encontram-se exibidas as categorias de dois primeiros dígitos que foram selecionadas por qualquer um dos testes aplicados (colunas 1 e 5 ). As colunas 2 e 6 mostram as frequências relativas desses dígitos na planilha, de acordo com o Teste dos Dois Primeiros Dígitos. As colunas 3 e 7 correspondem à proporção de cada somatório de preços totais dentro de determinada categoria de dois dígitos, segundo calculado no Teste da Soma. As colunas 4 e 8 apresentam a confirmação 
ou não da criticidade desses dígitos, de modo a definir quais deles serão incluídos na amostra de auditoria.

O confronto entre os testes sugere excluir os dois primeiros dígitos 72, 76, 82 e 83 da análise. Portanto, essa metodologia sugere os seguintes pontos críticos para o processo de auditoria: 10, 11, 15, 20, 21, 22, 23, 28, 29, 39, 42, 53, 59, 61, 62, 71 e 79.

5a Etapa: valor da amostra selecionada

Deve ser calculado o valor total da amostra em termos financeiros, fazendo uma varredura na planilha orçamentária, para buscar quais serviços possuem as categorias de dois primeiros dígitos críticos selecionados na etapa anterior.

Cabe ressaltar que, como este exemplo trata de preços totais, os somatórios dos valores totais referentes aos serviços de cada categoria de dígitos poderiam ser obtidos no próprio Teste da Soma, na coluna Soma.

Tabela 6 - Somatório de cada categoria de dois primeiros dígitos considerados críticos

Fonte: Elaboração própria, 2017

\begin{tabular}{|c|c|}
\hline Dois primeiros dígitos críticos & Somatório dos valores totais $\mathbf{R} \mathbf{\$}$ \\
\hline 10 & $17.954 .753,01$ \\
\hline 11 & $11.400 .040,89$ \\
\hline 15 & $35.997 .509,51$ \\
\hline 20 & $26.641 .371,16$ \\
\hline 21 & $5.870 .070,91$ \\
\hline 22 & $25.564 .236,26$ \\
\hline 23 & $4.510 .248,28$ \\
\hline 28 & $6.801 .977,59$ \\
\hline 29 & $7.927 .551,81$ \\
\hline 39 & $1.630 .744,74$ \\
\hline 42 & $6.391 .540,45$ \\
\hline 53 & $1.137 .267,64$ \\
\hline 59 & $1.092 .586,79$ \\
\hline 61 & $1.262 .767,79$ \\
\hline 62 & $12.759 .513,57$ \\
\hline 71 & $8.656 .078,00$ \\
\hline 79 & $9.175 .340,37$ \\
\hline Valor total obtido na amostra & $184.773 .598,77$ \\
\hline
\end{tabular}

\section{6a Etapa: comparação da amostra com o valor total do orçamento}

É necessário verificar o quanto a amostra selecionada representa em termos percentuais em relação ao valor total do orçamento.

Caso ela se aproxime dos $80 \%$ estipulados na 1a etapa, com uma diferença de, no máximo, 5\% para mais ou para menos, então é necessário seguir para a 7ạ etapa. 
Se a amostra for mais de $5 \%$ inferior aos $80 \%$ estabelecidos, deve-se relaxar o critério de seleção do Teste da Soma reduzindo o limite mínimo do resultado em $25 \%(0,011 \times(1-0,25))$ para aumentar o seu tamanho.

No caso de a amostra ser mais de $5 \%$ superior aos $80 \%$, deve-se aumentar o limite mínimo do resultado em $25 \%(0,011$ x 1,25) para reduzi-la.

Se, mesmo adotando todos esses critérios, for obtida uma amostra com o percentual muito inferior a $80 \%$ do valor total do orçamento, é preciso aumentar o nível de significância de 5\% para 10\% no Teste dos Dois Primeiros Dígitos e retornar à 2a Etapa (ii).

Neste exemplo, a amostra selecionada, utilizando os parâmetros básicos,

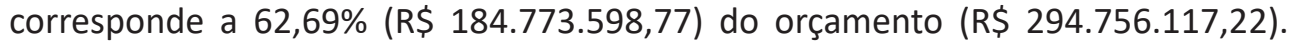
Como ela é mais de $5 \%$ inferior aos $80 \%$ estabelecidos, deve-se relaxar o critério de seleção do Teste da Soma reduzindo o limite mínimo do resultado em $25 \%$ $(0,011 \times(1-0,25)=0,00825)$ para aumentar o seu tamanho, agregando à amostra apenas os dois primeiros dígitos 12 . Contudo, o custo total da amostra passaria a ser $\mathrm{R} \$ 1$ 190.712.314,39, que corresponderia a $64,70 \%$ do custo total estimado, ou seja, não atingiríamos ainda os $80 \%$ almejados.

Mesmo ao se relaxar mais ainda o critério de seleção do Teste da Soma, reduzindo o limite mínimo em mais $25 \%(0,011 \times(1-0,50)=0,0055)$, nenhuma outra categoria de dois primeiros dígitos seria adicionada.

Foi realizada uma última tentativa em se reduzir o limite mínimo do Teste da Soma em mais $25 \%(0,011 \times(1-0,75)=0,00275)$, que agregou à amostra as categorias de dígitos 13, 14, 27 e 31, aumentando o seu valor para $R \$ 208.312 .859,00$ (70,67\%).

Como foram esgotadas todas as tentativas com o Teste da Soma, foi preciso alterar o nível de significância de $5 \%$ para $10 \%$ no Teste dos Dois Primeiros Dígitos e retornar à 2a Etapa, adotando como limiar do Teste Z o valor de 1,64. Embora três novas categorias tenham sido selecionadas de acordo com o Teste dos Dois Primeiros Dígitos (66, 88 e 96), nenhuma delas passou no confronto com o Teste da Soma, em função de sua baixa relevância financeira.

\section{7a Etapa: amostra de auditoria}

A amostra de auditoria final, sugerida por esta metodologia é $\{10,11,12,13,14$, $15,20,21,22,23,27,28,29,31,39,42,53,59,61,62,71,79\}$, cujo valor total de $\mathrm{R} \$ 208.312 .859,00$ corresponde a $70,67 \%$ do orçamento (mais de $5 \%$ inferior aos $80 \%$ estabelecidos inicialmente). Verifica-se que muitos dos itens que compõem a amostra não foram auditados pelo TCU. Portanto, seria possível, caso essa amostra fosse de fato auditada, encontrar itens com sobrepreço não detectados pela tradicional Curva ABC. 
8a Etapa: complementação da amostra adotando os critérios da Curva ABC

Se a amostra final ainda assim continuar com o valor muito baixo, então o algoritmo não é capaz de selecionar itens suficientes com base exclusivamente no critério da Lei Benford. Nesse caso, a amostra pode ser complementada com outro critério, tal como o custo dos serviços, da mesma forma adotada na metodologia da Curva $A B C$. Esse complemento final não será introduzido neste trabalho, já que a análise do TCU, adotada como referencial de mercado neste trabalho, abrange apenas $65,61 \%$ do valor total do orçamento.

\section{Confronto entre o resultado do algorítmo e a análise do TCU}

Com base na Tabela 7, a seguir, ao se confrontarem os dígitos selecionados pelos testes aplicados com as reduções no orçamento promovidas pela Infraero, identificaram-se 24 serviços da Curva $A B C$ que tiveram seus preços reduzidos ( $R \$ 51.690 .164,28)$. Somente para os dois primeiros dígitos 27, 39, 53 e 59 não foram efetuados ajustes pela Infraero.

Os dois primeiros dígitos 79 , considerados os mais críticos por terem sido identificados tanto no Teste dos Dois Primeiros Dígitos, quanto no Teste da Soma, antes de se relaxar os critérios estipulados pelo algoritmo, correspondiam ao Item 03.01.260.01 - Caixilho especial e antichama [...], o qual foi suprimido do orçamento pela entidade, resultando em uma diminuição do valor do contrato em quase oito milhões de reais (preços de set./2010).

Tabela 7-Dígitos de serviços que sofreram redução pela Infraero e foram detectados pela Lei de Benford - reforma do Aeroporto Internacional Tancredo Neves

\begin{tabular}{|c|c|c|c|c|c|}
\hline Díg. & Item & Descrição & Un. & Preço total & Ajuste Infraero \\
\hline 10 & $\begin{array}{c}\text { 04.03.130.01+ } \\
04.05 .130 .01-\mathrm{A} \\
+04.05 .130 .01 \\
-\mathrm{B}\end{array}$ & $\begin{array}{l}\text { Fornecimento e aplicação de } \\
\text { concreto (fck=30MPa) }\end{array}$ & $\mathrm{m}^{3}$ & $3.117 .950,07$ & $1.058 .469,86$ \\
\hline \multirow{4}{*}{11} & 10.01.200.06 & $\begin{array}{c}\text { Tubulação em aço carbono preto } \\
\text { sem costura ASTM A-53 grau B } \\
\text { Schedule 40- Dimensão } \varnothing 8 "\end{array}$ & $\mathrm{~m}$ & $1.192 .873,00$ & $679.569,00$ \\
\hline & 10.01 .610 .03 & $\begin{array}{l}\text { Chapa de aço galvanizada \#22 (rede } \\
\text { de dutos) }\end{array}$ & $\mathrm{kg}$ & $1.189 .466,28$ & 796.989,96 \\
\hline & 03.01.120.01.01 & $\begin{array}{l}\text { Painel divisória em alumínio } \\
\text { anodizado na cor natural com vidro } \\
\text { em composição com painéis em } \\
\text { alumínio com madeira [...] }\end{array}$ & $\mathrm{m}^{2}$ & $1.146 .923,91$ & $914.443,83$ \\
\hline & 03.01 .600 .05 & $\begin{array}{l}\text { Pintura em hidrofugante à base de } \\
\text { silicone }\end{array}$ & $\mathrm{m}^{2}$ & $1.192 .681,60$ & $651.231,26$ \\
\hline
\end{tabular}




\begin{tabular}{|c|c|c|c|c|c|}
\hline Díg. & Item & Descrição & Un. & Preço total & Ajuste Infraero \\
\hline 12 & 10.04.100.02.01 & $\begin{array}{l}\text { Conjunto de esteiras de bagagens } \\
\text { coletoras (EC) completas }\end{array}$ & un & $1.287 .063,72$ & $148.738,92$ \\
\hline 13 & 04.03.110.01 & $\begin{array}{l}\text { Forma plana para estruturas de } \\
\text { concreto, fornecimento e aplicação }\end{array}$ & $\mathrm{m}^{2}$ & $1.501 .171,17$ & $142.711,09$ \\
\hline 14 & $\begin{array}{l}04.03 .110 .01 \\
\text { (ITEM JÁ } \\
\text { IDENTIFICADO) }\end{array}$ & $\begin{array}{l}\text { Forma plana para estruturas de } \\
\text { concreto, fornecimento e aplicação }\end{array}$ & $\mathrm{m}^{2}$ & $1.501 .171,17$ & $142.711,09$ \\
\hline \multirow[b]{2}{*}{15} & $\begin{array}{c}\text { 03.01.510.04.01 } \\
+ \\
\text { 03.01.510.04.02 }\end{array}$ & $\begin{array}{c}\text { Piso em granito branco polar, placas } \\
\text { de } 40 \times 40 \mathrm{~cm} \text {, acabamentos polido/ } \\
\text { levigado, espessura } 2 \mathrm{~cm}\end{array}$ & $\mathrm{~m}^{2}$ & $15.869 .236,31$ & $8.582 .755,09$ \\
\hline & $\begin{array}{c}\text { 04.03.130.01 + } \\
04.05 .130 .01-\mathrm{A} \\
+04.05 .130 .01 \\
\text { - B (ITEM JÁ } \\
\text { IDENTIFICADO) }\end{array}$ & $\begin{array}{l}\text { Fornecimento e aplicação de } \\
\text { concreto (fck=30MPa) }\end{array}$ & $\mathrm{m}^{3}$ & $3.117 .950,07$ & $1.058 .469,86$ \\
\hline \multirow{3}{*}{20} & 10.06.100.01 & $\begin{array}{c}\text { Pontes de embarque doméstico } \\
\text { (P01, P02, P03, P04, P05, P06 e } \\
\text { P07), [...] }\end{array}$ & un & $20.722 .800,00$ & $9.547 .397,07$ \\
\hline & 03.01 .340 .02 & $\begin{array}{c}\text { Guarda-corpo em vidro laminado } \\
\text { incolor } 20 \mathrm{~mm} \text {, dois vidros de } 10 \mathrm{~mm} \\
\text { cada }[\ldots]\end{array}$ & $\mathrm{m}$ & $2.020 .312,70$ & $880.664,96$ \\
\hline & $\begin{array}{l}04.03 .120 .01+ \\
04.05 .120 .01-\mathrm{A} \\
+04.05 .120 .01 \\
-\mathrm{B} \\
\end{array}$ & $\begin{array}{l}\text { Fornecimento, corte, dobra e } \\
\text { montagem de aço CA-50 }\end{array}$ & $\mathrm{kg}$ & $5.400 .052,36$ & $2.099 .945,06$ \\
\hline \multirow{3}{*}{21} & 10.01.610.02 & $\begin{array}{l}\text { Chapa de aço galvanizada \#24 (rede } \\
\text { de dutos) }\end{array}$ & kg & $2.113 .471,20$ & $1.451 .051,75$ \\
\hline & 02.02.100.01 & $\begin{array}{c}\text { Mobilização de pessoal e } \\
\text { equipamentos }\end{array}$ & cj & $212.422,88$ & $8.310,48$ \\
\hline & 02.02 .100 .04 & $\begin{array}{c}\text { Desmobilização de pessoal e } \\
\text { equipamentos }\end{array}$ & cj & $212.422,88$ & $8.310,48$ \\
\hline 22 & 02.02 .100 .02 & $\begin{array}{l}\text { Administração local e manutenção } \\
\text { do canteiro }\end{array}$ & mês & $22.366 .893,36$ & $3.751 .114,36$ \\
\hline 23 & $\begin{array}{c}\text { 04.03.120.01 + } \\
04.05 .120 .01-\mathrm{A} \\
+04.05 .120 .01 \\
-\mathrm{B}(\mathrm{JÁ} \\
\text { IDENTIFICADO) }\end{array}$ & $\begin{array}{l}\text { Fornecimento, corte, dobra e } \\
\text { montagem de aço CA-50 }\end{array}$ & $\mathrm{kg}$ & $5.400 .052,36$ & $2.099 .945,06$ \\
\hline \multirow{2}{*}{28} & $\begin{array}{c}\text { 02.01.100: } \\
02.01 .100 .01 \mathrm{a} \\
02.01 .100 .10\end{array}$ & $\begin{array}{c}\text { Edificações de madeira, em } \\
\text { painéis modulados, conforme } \\
\text { projeto específico (fornecimento e } \\
\text { execução) }\end{array}$ & cj & $2.827 .694,35$ & $725.892,14$ \\
\hline & 03.01 .230 .02 .16 & $\begin{array}{c}\text { CF23 - 13,71 x 4,28 m (caixilho fixo } \\
\text { structural glazing ou pele de vidro } \\
{[\ldots]}\end{array}$ & un & $280.174,93$ & $155.108,24$ \\
\hline
\end{tabular}




\begin{tabular}{|c|c|c|c|c|c|}
\hline Díg. & Item & Descrição & Un. & Preço total & Ajuste Infraero \\
\hline 29 & 10.04 .200 .01 .01 & $\begin{array}{c}\text { Carrosséis de restituição de } \\
\text { bagagens - desembarque } \\
\text { doméstico: }[\ldots]\end{array}$ & un & $2.988 .527,52$ & $1.049 .008,62$ \\
\hline 31 & 10.04.100.05.01 & $\begin{array}{c}\text { Carrossel de embarque de } \\
\text { bagagens }\end{array}$ & un & $3.194 .765,00$ & $1.843 .934,76$ \\
\hline 42 & 10.04.100.03.01 & $\begin{array}{c}\text { Conjunto de esteiras } \\
\text { transportadoras de ligação (EL) } \\
\text { completas, com acessórios } \\
\text { elétricos, eletrônicos e mecânicos } \\
{[\ldots]}\end{array}$ & un & $4.235 .242,62$ & $1.902 .676,16$ \\
\hline 61 & 10.01.300.09 & $\begin{array}{c}\text { Isolamento térmico em tubo } \\
\text { de borracha elastomérica } \varnothing 4 " \\
\text { espessura } 25 \mathrm{~mm}[\ldots]\end{array}$ & & $615.418,44$ & $357.997,90$ \\
\hline 62 & 10.06.100.02 & $\begin{array}{l}\text { Pontes de embarque internacional } \\
\text { (P08 e P09), modelo Apron drive [..] }\end{array}$ & un & $6.290 .850,00$ & $3.097 .877,73$ \\
\hline \multirow[b]{2}{*}{71} & 10.05 .100 .01 & $\begin{array}{c}\text { Escadas rolantes: ER-01, ER-02, } \\
\text { ER-03, ER-04, ER-05, ER-06, ER-07 e } \\
\text { ER-08 [...] }\end{array}$ & cj & $7.104 .960,00$ & $3.831 .126,32$ \\
\hline & $\begin{array}{c}\text { 04.03.120.01+ } \\
04.05 .120 .01-\mathrm{A} \\
+04.05 .120 .01 \\
-\mathrm{B}(\mathrm{JÁ} \\
\text { IDENTIFICADO) }\end{array}$ & $\begin{array}{l}\text { Fornecimento, corte, dobra e } \\
\text { montagem de aço CA-50 }\end{array}$ & $\mathrm{kg}$ & $5.400 .052,36$ & $2.099 .945,06$ \\
\hline \multirow[t]{2}{*}{79} & 03.01 .260 .01 & $\begin{array}{c}\text { Caixilho especial e antichama } \\
\text { em aço inox a prova de fogo, } \\
\text { com isoladores e materiais } \\
\text { intumescentes }[\ldots]\end{array}$ & $\mathrm{m}^{2}$ & $7.979 .969,71$ & $7.979 .969,71$ \\
\hline & & & & Total & $51.690 .164,28$ \\
\hline
\end{tabular}

Fonte: Dados fornecidos pelo TCU e elaboração própria, 2017.

O somatório das reduções enumeradas na última coluna da Tabela 7 foi $\mathrm{R} \$ 51.690 .164,28$, que representava $86,66 \%$ do total das reduções nos preços (R\$ 59.645.479,61).

A Secretaria de Obras do TCU disponibilizou tabela ${ }^{5}$ contendo os itens da Curva $A B C$ que foram ajustados pela Infraero. A amostra contemplada nessa tabela referese a $\mathrm{R} \$ 193.387 .999,24$, que representa apenas $65,61 \%$ do valor total do orçamento analisado ( $R \$ 294.756 .117,22)$.

Ressalte-se que a Corte de Contas, inicialmente, analisou e questionou apenas $48,56 \%$ dos serviços da planilha orçamentária da obra ora analisada, ou seja, não

\footnotetext{
${ }^{5}$ A tabela não foi incluída neste trabalho em benefício do espaço. Caso o leitor tenha interesse, favor solicitar a tabela aos autores.
} 
conseguiu realizar o exame de $80 \%$ do orçamento utilizando a tradicional Curva $A B C$. Os ajustes efetuados pela Infraero, ocorridos em resposta a essa análise, poderiam ter sido maiores caso o Tribunal tivesse examinado um número maior de itens e encontrasse um sobrepreço mais alto. Mais fundamentalmente, estimase que maior economia poderia ter sido feita caso todos os itens sugeridos pela nova metodologia tivessem sido auditados. Um estudo comparativo, envolvendo duas auditorias simultâneas, uma baseada na Curva $A B C$ e outra baseada na nova metodologia é sugerido na conclusão como proposta de pesquisa futura.

\section{Conclusão}

Este trabalho testou a aplicação de algoritmo baseado na Lei Benford, proposto por Bugarin e Cunha (2015) e detalhado didaticamente em uma cartilha por Cunha, Bugarin e Portugal (2016), aos preços totais do orçamento da obra de reforma do Aeroporto Internacional Tancredo Neves em Minas Gerais, no valor de $\mathrm{R} \$$ 294.756.117,22 (preços de set./2010). O método foi desenvolvido recentemente para facilitar a seleção da amostra de auditora de obras públicas pelos órgãos de controle e pesquisadores em geral. O objetivo principal da metodologia é apontar quais itens têm a maior probabilidade de terem sofrido manipulação e, portanto, estarem com os preços superestimados e selecionar esses itens para auditoria. Este é o primeiro trabalho a aplicar o algoritmo a uma obra de aeroporto, e tal aplicação, por ter sido bem sucedida, trará mais segurança aos interessados.

Foram apresentados: os testes da Lei de Benford baseados nas frequências dos dígitos; um resumo da auditoria do TCU na obra de reforma do Aeroporto Internacional Tancredo Neves (MG); a metodologia baseada no algoritmo supracitado aplicada à obra em tela; e o confronto entre os resultados obtidos com o uso do algoritmo e a análise do TCU.

O custo total dos itens na amostra selecionada pela nova metodologia é S =

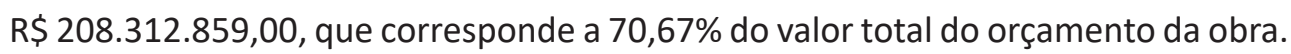
Verifica-se que muitos dos itens que compõem a amostra $S$ não foram auditados pelo TCU. Portanto, não é possível afirmar, caso essa amostra tivesse de fato sido auditada, se haveria achados de sobrepreço não detectados pela tradicional Curva ABC. Todavia, observa-se que essa metodologia foi capaz de detectar $86,66 \%$ ( $R \$$ 51.690.164,28 - data-base set/2010) das reduções nos preços do orçamento da obra em tela promovidas pela Infraero, após fiscalização do TCU, segundo dados fornecidos pela Corte de Contas.

Toda essa análise realizada com base no algoritmo teve o intuito de selecionar a amostra de auditoria em uma forma possivelmente mais eficiente do que a proposta pela Curva $A B C$. Isso porque a Curva $A B C$ consiste apenas na seleção dos itens com 
valores mais altos da planilha enquanto a Lei de Benford seleciona a amostra de auditoria com base em indícios de manipulação dos valores dos serviços. Contudo, mais pesquisas são necessárias para comparar a efetividade das duas metodologias. Propomos, como sugestão para pesquisas futuras, que duas equipes de auditores realizem simultaneamente auditorias, uma utilizando a metodologia derivada da Lei de Benford e a outra usando a tradicional Curva $A B C$, comparando, ao final, os resultados encontrados.

É digno de nota discutir o possível futuro da manipulação de dados nas aquisições governamentais. Ao menos no Brasil, a Lei Newcomb-Benford ainda não é aplicada como uma ferramenta complementar regular pelos tribunais de contas, o que pode explicar, em parte, o resultado significativamente positivo encontrado nesta análise. Caso essa ferramenta se torne padrão, as empresas podem ficar alertas para isso e desenvolver formas mais sofisticadas de superestimar seus ganhos, no intuito de evitar a fiscalização. Entretanto, assim como nós tentamos mostrar na aplicação dos Testes do Primeiro Dígito, dos Dois Primeiros Dígitos e da Soma, a Lei de Benford é uma ferramenta muito rica, e diversos testes alternativos podem ser aplicados para um único banco de dados. Por exemplo, há também um teste específico para o segundo dígito. Considerando que pode ser viável manipular os dados mantendo as frequências relativas dos primeiros dígitos compatíveis com a Lei de Benford, será muito mais difícil manter os dados também em conformidade com as frequências relativas esperadas dos dois primeiros dígitos, segundo dígito e soma dos valores dentro de cada categoria. Além disso, testes adicionais são desenvolvidos constantemente e novas leis podem ser usadas alternativamente, como a Lei de Zipf (ODUEKE; WeIR, 2012), que é, de forma específica, uma generalização da Lei de Benford.

\section{Referências bibliográficas}

AZEVEDo FILHo, R. N. Fraude em licitações e a Lei de Benford - aplicação em perícias de engenharia civil do DPF. In: Seminário de Perícias de Engenharia da Polícia FEDERAL, 8., 2016, Maceió. Anais... Maceió, 2016.

BENFORD, F. The law of anomalous numbers. Proceedings of the American Philosophical Society, v. 78, n. 4, p. 551-572, 1938.

BERTON, L. He's got their number: scholar uses math to foil financial fraud. Wall Street Journal, v. 10, B1. jul. 1995.

BugARIN, M.; CUNHA, F. C. R. A didactic note on the use of Benford's Law in public works auditing, with an application to the construction of the Brazilian "Amazon Arena" 2014 World Cup soccer stadium. Economia, Japão, v. 66, p. 23-55, 2015.

BustA, B.; WEINBERG, R. Using Benford's law and neural networks as a review procedure. Managerial Auditing Journal, v.13, n. 6, p. 256-366, 1998. 
CAFÉ, R. M. O uso da Lei de Benford na auditoria de obras públicas: o caso do VLP. Trabalho de Conclusão de Curso (Monografia Bacharelado em Economia) Universidade de Brasília, Brasília, 2015.

CHO, W. K. T.; GAINES, B. J. Breaking the (Benford) Law: statistical fraud detection in campaign finance. The American Statistician, v. 61, p. 218-223, 2007.

CunHA, F. C. R. Aplicações da Lei Newcomb-Benford à auditoria de obras públicas. Dissertação (Mestrado em Regulação e Gestão de Negócios) - Universidade de Brasília, Brasília, 2013. 486p.

CunhA, F. C. R.; BugARIN, M. Lei de Benford e auditoria de obras públicas: uma análise de sobrepreço na reforma do Maracanã. Revista TCU, v. 46, n. 131, p. 46-53, 2014.

Benford's law for audit of public works: an analysis of overpricing in Maracanã soccer arena's renovation. Economics Bulletin, v. 35, n. 2, mai. 2015a.

Lei de Benford para a auditoria de obras públicas: análise de sobrepreço na construção da Arena da Amazônia. Boletim de Licitações e Contratos (BLC/NDJ), v. 28, n. 8, p. 841-857, 2015b.

Cunha, F. C. R.; Bugarin, M.; Portugal, A. Seleção de amostra de auditoria de obras públicas pela Lei de Benford. Florianópolis: Instituto Brasileiro de Auditoria de Obras Públicas (Ibraop), 2016 (no prelo).

DRAKE, P. D.; NIGRINI, M. J. Computer assisted analytical procedures using Benford's law. The Accounting Education, v. 18, p. 127-146, 2000.

DURTSCHI, C.; HILLISON, W.; PACINI, C. The effective use of Benford's Law to assist in detecting fraud in accounting data. Journal of Forensic Accounting, v. 5, p. 17-34, 2004.

EUROPEAN COMMISSION. Report on Greek government deficit and debt statistics. 2010. Disponível em: <http://epp.eurostat.ec.europa.eu/portal/page/portal/ product_details/publication?p_product_code=COM_2010_report_greek> Acesso em: 24/03/2014.

GILES, D. E. Benford's law and naturally occurring prices in certain ebay auctions. Applied Economics Letters, v. 14, n. 3, p.157-161, 2007.

HILL, T. P. Base-invariance implies Benford's Law. The American Mathematical Society, v. 123, n. 3, p. 887-895, 1995. ISSN: 0002-9939

HÜRLIMANN, W. Benford's Law from 1881 to 2006: a bibliography. 2006. Disponível em: <https://arxiv.org/ftp/math/papers/0607/0607168.pdf> Acesso em: 15/03/2017.

LU, F.; BORITZ, J. E. Detecting fraud in health insurance data: learning to model incomplete Benford's Law distributions. In: GAMA, J.; CAMACHO, R.; BRAZDIL, P. B.; JORGE, A. M.; TORGO, L. (Eds.). Machine Learning: ECML, 2005. ECML 2005. Lecture Notes in Computer Science, v. 3720. Springer, Berlin, Heidelberg, 2005.

Mebane, W. R. Election forensics: vote counts and Benford's Law. The Society for Political Methodology, Papers, Posters and Syllabi, n. 620, 2006.

Note on the presidential election in Iran. Ann Arbor: University of Michigan, 2009. 
Fraud in the 2009 presidential election in Iran? Chance, v. 23, n. 1, p. 6-15, 2010.

NEWCOMB, S. Note on the frequency of the different digits in natural numbers. The American Journal of Mathematics, v. 4, p. 39-40, 1881.

NIGRINI, M. J. The detection of income tax evasion through an analysis of digital frequencies. Ph.D. thesis. Cincinnati, OH: University of Cincinnati, 1992.

Digital analysis using Benford's Law: tests statistics for auditors. Global Audit Publication, 2000.

Benford's Law. Applications for forensic accounting auditing, and fraud detection. Hoboken, New Jersey: John Wiley \& Sons, Inc., 2012.

PINKHAM, R. S. On the distribution of first significant digits. Annals of Mathematical Statistics, v. 32, p. 1223-1230, 1961.

ODUeKe, A.; WeIR, G. Triage in forensic accounting using Zipf's Law. In: WeIR, G.; ALNEMRAT, A. Issues in cybercrime, security and digtal forensics. Glasgow: University of Strathclyde Publishing, 2012. p. 33-43.

RAUCH, B.; GÖTTSCHE, M.; BRÄHLER, G.; ENGEL, S. Fact and fiction in EU-governmental economic data. German Economic Review, v. 12, n. 3, p. 243-255, 2011. Disponível em: <http://onlinelibrary.wiley.com/doi/10.1111/j.1468-0475.2011.00542.x/ abstract> Acesso em: 09/08/2015.

\section{Maurício Soares Bugarin}

Possui PhD em Economics pela University of Illinois, Estados Unidos. Atualmente é professor titular do Departamento de Economia da Universidade de Brasília (UnB). Contato: bugarin.mauricio@gmail.com

\section{Flávia Ceccato Rodrigues da Cunha}

Possui mestrado profissionalizante em Regulação e Gestão de Negócios pela Universidade de Brasília (UnB). Atualmente é Auditora Federal de Controle Externo do Tribunal de Contas da União. Contato: flaviaceccato@hotmail.com 